Review Article

\title{
Can Repetitive Small Magnitude-Induced Seismic Events Actually Cause Damage?
}

\author{
Oliver-Denzil S. Taylor ${ }^{(D},{ }^{1}$ Alanna P. Lester, ${ }^{1}$ Theodore A. Lee III, ${ }^{2}$ and Mihan H. McKenna ${ }^{1}$ \\ ${ }^{1}$ U.S. Army Corps of Engineers, Engineer Research and Development Center, Geotechnical and Structures Laboratory, Vicksburg, \\ MS 39180, USA \\ ${ }^{2}$ U.S. Army Corps of Engineers, Engineer Research and Development Center, USACE Reachback Operations Center, Mobile, \\ AL 36602, USA
}

Correspondence should be addressed to Oliver-Denzil S. Taylor; oliver.d.taylor@usace.army.mil

Received 12 January 2018; Accepted 10 April 2018; Published 8 May 2018

Academic Editor: Tiago Miguel Ferreira

Copyright (c) 2018 Oliver-Denzil S. Taylor et al. This is an open access article distributed under the Creative Commons Attribution License, which permits unrestricted use, distribution, and reproduction in any medium, provided the original work is properly cited.

\begin{abstract}
Geoengineering activities such as reservoir impoundment, mining, wastewater injection, geothermal systems, and $\mathrm{CO}_{2}$ capture have been linked directly to induced seismicity. With the industrial boom in natural shale gas production regions previously aseismic areas have seen an exponential growth in the frequency of small magnitude events, with multiple events observed in close proximity within a 24-hour time period. While the overwhelming majority of induced seismic research has focused on the causality, the potential risk posed to critical federal infrastructure has escaped scrutiny. This proposes the question, "Can repetitive small magnitude-induced seismic events actually cause damage?" A review of the potential risk is presented herein, concluding that a simplistic definitive statement of whether single or multiple small magnitude-induced seismic events do or do not cause damage to critical infrastructure cannot be justified, and warrants additional study. However, recent observations and research suggest the likelihood that these geoengineering-induced events can and do cause detrimental degradation of the subsurface (damaging the overlying structure) is not insignificant.
\end{abstract}

\section{Introduction}

Recent induced seismic research has shown that the current standard of practice for risk assessment for infrastructure is not applicable for the UHP-induced seismic hazard in historically aseismic continental regions $[1,2]$ but is critically important for understanding the immediate impact potential to USACE-owned dams and levees throughout the Central and southwest central United States (CeUS). Engineering, economic, social, and political decision-making matrices must therefore, include the questions of "What is the largest expected induced seismic event?" and "What is the probability of an induced seismic event generating a potentially damaging ground motion?" The answers to these questions are currently the focus of emerging research [1-4].

Intraplate regions are primed to be susceptible to induced earthquakes, as the geological stress states are already at critical stress conditions: the geological structure is in a quasistatic equilibrium state [3,5-7]. Recent advances in fluid-based geoengineering activities, hydraulic fracturing/ enhanced recovery technology, population growth, and worldwide energy consumption rates are suspected of contributing to the exponential increase in seismic activity within these historically aseismic regions by altering deep lithology effective stress states, which result in subsurface shear failure [1-3, 5, 6, 8-20]. Seismologists and earthquake engineers have recently issued concerns about fluid-based geoengineering activities being the genesis of moderate induced seismicity $[1,2,4,19-21]$, yet the topic of damage potential of geoengineering-induced seismicity remains relatively unexplored.

\section{Geoengineering-Induced Seismicity}

The exponential rise in induced seismicity in the CeUS since 2008 is correlated with an increase in Modified Mercalli Intensities (MMI) from small, relatively shallow events $[1,2,5,22]$. Common geophysical practice adheres to the 
premise that seismicity below M5.0 is not significant for generating damaging ground motions and, thus, is not considered a substantial hazard to critical infrastructure $[1,2,4]$. Increased MMI combined with encroaching spatiotemporal proximity to critical infrastructure begs the question, "Could future small magnitude-induced events affect federal flood control structures and critical infrastructure?" This is particularly important to the aging infrastructure within the United States where some critical structures are beyond design life spans and/or designed without any seismic considerations [23].

This recent rise in seismicity within the CeUS appears to be different from what has been historically observed as these events are more shallow (typically between 2 and $5 \mathrm{~km}$ in depth as opposed to $10+\mathrm{km}$ for historically tectonic events), are smaller in magnitude, are persistent, and occur in previously essentially aseismic areas [3, 24-27]. It must be noted that the spatial location and average depth of recent events are loosely constrained due to instrument coverage and limitations within location algorithms, and some regions; for example, Oklahoma, have default depths of $5 \mathrm{~km}$ for shallow events, for events whose location accuracies are uncertain. However, the recent events reported are predominately occurring within the upper $5 \mathrm{~km}$ of the crust [24-27]. More important is the temporal frequency of these events. Recent research on the spatial-temporal behavior of geoengineering-induced seismicity shows that these events can be highly concentrated; for example, a single region in Arkansas exhibited 6.5 events per $\mathrm{km}^{2}$ at a rate of about 146 events per year between 2004 and 2013 [1,2]. Some regions in the CeUS average over two events daily.

\section{Damage Potential of Geoengineering-Induced Seismicity}

Small magnitude (between M3 and M5), shallow (2-5 km), geoengineering-induced seismic events have demonstrated damage to many types of structures. Nowhere is this more apparent than in aseismic intraplate regions wherein damage is observed from both single and repeated small, shallow events. A series of shallow events in Alberta, Canada (largest event M4.0), caused some minor building damage [19, 28]. Residential damage has been observed within the Central United States, for example, the 2012 Timpson, Texas sequence (largest event of $M_{W-R M T} 4.8$ ) [29] and the 2013 Azel, Texas sequence (largest event M3.7) [30]. In Cherokee, Oklahoma, there were several events on February 5, 2015 (largest event of M4.2) wherein interior walls were damaged in the Alfalfa County Courthouse [30-32]. In November 2014, an M4.9 event occurred in the vicinity of Milan, KS, with damage to the Harper County courthouse as well as to surrounding churches and residences; events continued through the spring of 2015 wherein new cracks generated and existing building cracks enlarged [9, 33-35]. On May 2, 2015, an M4.2 event occurred in Michigan with residential and commercial damage, for example, cracks in walls $[36,37]$. This by no means an all-inclusive list; however, it is typical of the seemingly inconsequential damage documented from induced seismicity. Could future small magnitude-induced events affect larger and heavier structures? Quinn and Taylor [38] showed fatigue failure potential from induced strains in earthen structures subjected to minor ground accelerations while under normal to slightly elevated service load and not necessarily limited to sudden catastrophic failure from a single large event. More importantly these damage reports indicate potentially more problematic hazards: (1) repetitive loading and (2) subsurface fatigue.

\section{Single-Event Failure versus Multievent Fatigue}

The repetitious nature of these events may generate cumulative damage effects, or fatigue, well in excess of the initial structural design. Moreover, these seemingly inconsequential dynamic loading scenarios are often dismissed as potentially damaging in favor of a single isolated event; that is, if a structure can withstand a much larger extreme event, then a minor event poses no significant threat. This would be a safe assumption provided that the occurrence frequency of the smaller events was not significant. For example, in Rhode Island, there have been numerous cases wherein vibrations caused by pile driving have resulted in detrimental settlement of adjacent structures (similar to the damage correlated with induced seismicity), leading to the demolition of some historic structures [39]. These vibrations were caused by impact hammers operating at low strike frequencies wherein each pile strike generated seismic velocities well below construction thresholds for even the most sensitive structures. Therefore, the question of damage potential becomes a source scaling issue.

Dynamic responses decay as a function of distance from an energy source. Finite seismic sources, for example, single induced events, in a bounded elastic media have a geometric amplitude decay of

$$
A_{2}=A_{1}\left(\frac{r_{1}}{r_{2}}\right)^{n},
$$

where $r_{1}$ is the radial distance from the source to a known amplitude, $A_{1} ; r_{2}$ is the radial distance to an unknown amplitude, $A_{2}$; and $n$ is the exponent of decay depending on the seismic wave type. Small magnitude events, M5-, at a shallow depth can yield surface ground motions well in excess of much larger, M7+, tectonic earthquakes simply due to a significantly reduced $r_{2}$. Thus, simply negating damage potential based strictly on magnitude determinations is both mathematically and physically incorrect. New ground motion prediction equations are required for these events $[4,40]$. Induced events have much shorter duration and higher frequency contents [19, 29]. For structures of low natural frequencies, single high-frequency peak acceleration would have little effect to the physical structure [41]. Therefore, it is unlikely that an induced event would cause significant damage to a large nonearthen structure. However, if we associate these induced events as an impulse force, that is, single-cycle large amplitude loading, the primary driver for damage potential is not the cyclic or frequency 
effects to the physical structure, rather the damage potential is the subsurface yield that can cause detrimental settlement and structural damage.

Engineers and geophysicists often consider the crustal pore space, regardless of air/water make-up, to be initially static. This assumption is valid for tectonic cases where earthquakes are years to decades apart. In regions of frequent induced seismicity, where events are hours to days apart, pore pressures are not necessarily static at the onset of subsequent induced events $[1,2]$. In terms of ground response for liquefiable cohesionless soils, excess pore pressure generation is relatively independent of loading frequency with dissipation being a function of permeability $[39,42]$. Moreover, excess pore pressure ratios do not need to achieve unity to cause significant strains within a cohesionless continuum; strains as low as $0.3 \%$ can indicate the onset of uncontrolled degradation within the subsurface [39]. This degradation, or strength reduction, may cause differential settlement beneath a structure leading to foundation damage or failures even though the physical structure would be negligibly affected by the induced seismic waveform. For example, a loose liquefiable nonplastic silt has a cyclic resistance ratio, CRR, of 0.187 at the onset of significant straining, Figure 1 (a M7.5 tectonic event corresponds to 15 equivalent loading cycles [43]); the CRR increases to approximately 0.294 for a single cycle equivalent. Thus, based on Seed and Idriss [44] and Seed et al. [45], the smaller magnitude-induced event would have to yield approximately 1.5 times increase in peak acceleration to initiate significant subsurface straining. For tectonic events, such acceleration is not achieved with a decrease in earthquake magnitude. However, for induced seismicity, (1) illustrates that such an increase in acceleration with a decrease in earthquake magnitude is possible due to the shallow hypocenter.

A typical earthen structure may have a minimum threshold equivalent acceleration of approximately $0.2 \mathrm{~g}$ before the onset of straining (damage) is believed to occur, typically referenced as 15 equivalent loading cycles. Therefore, in the case of loose liquefiable nonplastic silt lens, a single-cycle equivalent event, that is, induced seismic event, would require an acceleration of approximately $0.30 \mathrm{~g}$ to have the same damage potential. Peak accelerations in excess of this example have been observed in induced events, for example, $\mathrm{m}_{\mathrm{bLg}} 4.1$ Timpson, Texas, with peak accelerations of up to $0.62 \mathrm{~g}$ [29]. If the induced seismic event equivalent loading cycles increase to four, then the required acceleration to achieve the same $0.2 \mathrm{~g}$ threshold remains relatively unchanged at $0.27 \mathrm{~g}$, thus justifying a single induced event as impulse load. Repetitive induced events can then be treated as a low frequency loading equivalents with a sinusoidal maximum equivalent to the impulse.

Effects on smaller structures from high frequencies (both temporal and spectral), not the amplitude of the acceleration, can be observed at a significant distance from the epicenter and would observationally manifest in intensity reports. While aftershocks from tectonic events decrease in magnitude, induced seismicity magnitudes remain relatively constant for each subsequent event making the impulse load relatively constant with each event $[1,2]$. Thus, it is

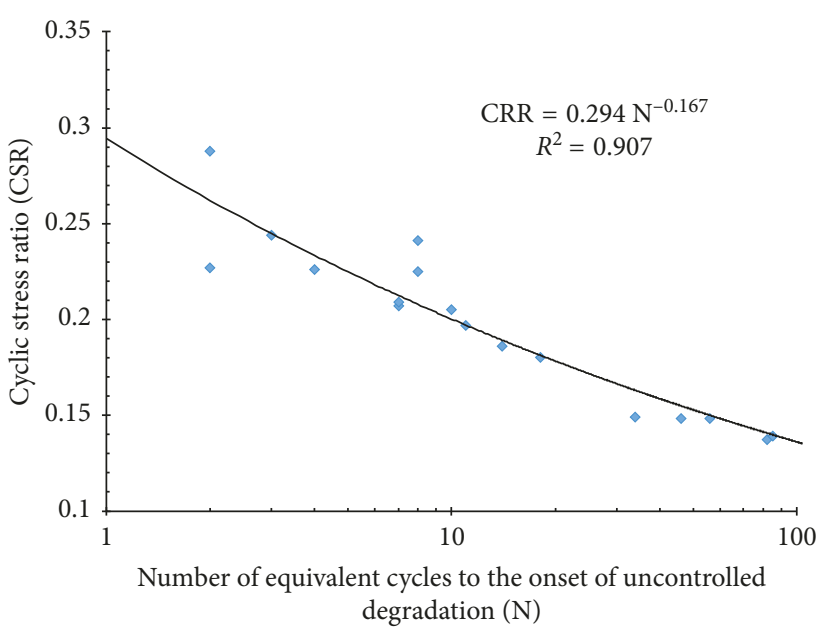

Figure 1: The cyclic resistance, to the onset of uncontrolled degradation, of a loose to medium dense nonplastic Rhode Island silt (after 40).

misleading to compare tectonic earthquakes and induced seismicity without accounting explicitly for variance in loading mechanisms. In regions of frequent induced seismicity, structures subjected to repetitive impulse loadings do not consider soil fatigue states. Such conditions are explicitly accounted in for other aspects of civil engineering, for example, traffic vibration in bridge design, in either design, or assessment processes and should be included in discussions of the subsurface damage potential for induced seismicity, due to the risk to the overall stability.

There are unknown effects that may increase the damage potential from induced seismicity, for example, the large vertical acceleration component as observed in Timpson, Texas [29]. Our understanding of seismic loading is based on tectonic events that manifest as large horizontal ground motions with minimal influence from the vertical component, which is often ignored. This change in loading direction alters the shearing axis and therefore the soil's capacity to resist the imparted load. Further, an applied shear load propagating vertically from the subsurface is more representative of an extension type loading; this is the weakest axis for soil resistance and warrants further study.

\section{Hazard and Risk}

Induced seismic events do not carry the same hazard as large tectonic equivalents. In tectonic events, the radial extent of large ground motions exceeds that of what has been observed in shallow induced seismicity. Therefore, the associative risk to critical infrastructure, of a single induced seismic event, would decrease in comparison, based on how risk is calculated [46]:

$$
\text { Seismic Risk = Seismic Hazard } \Theta \text { Vulnerability. }
$$

The Vulnerability of any structure is a function of exposure (within the proximity of the seismic event such that it may potentially be affected), fragility (susceptibility of the structure to the ground intensities), and consequence (socioeconomic impact should failure occur) [22]. In (2), the 
Seismic Hazard, or probability of exceedance of a specified ground motion intensity, for tectonic events (the PGA, PGV, spectral content, etc.) can readily exceed that of induced events $[1,2]$ on a per event basis. However, the close spatial proximity and repetitious nature of induced events actually increase the exposure or the chance that an induced epicenter will occur within sufficient proximity to exceed a threshold acceleration by increasing the probability of an event occurrence, shown in the $b$-value for induced events $[1,2]$.

Quinn and Taylor [38] illustrated that in the case of earthen dams, normal to slight increases in one hazard (e.g., the impounded water head) can reduce the required seismic hazard threshold for exceedance. In this scenario, the Seismic Risk would be a joint probability function of the Seismic Hazard and the secondary hazard (e.g., flood event). It is then possible that repetitive low magnitudeinduced events combined with a secondary hazard result in a higher Seismic Risk, or failure potential, than a larger tectonic event. This may yield a situation where the structural design is insufficient and the probability of occurrence is greater for the joint-induced seismic-secondary hazard event despite the structure being designed for a larger single tectonic event.

\section{Conclusions}

The answer to "Can repetitive small magnitude-induced seismic events actually cause damage?" requires a better understanding of the extent of failure modes (classic failure versus soil fatigue) and threshold limits within the seismic hazard, and vulnerability of structures ill-equipped to withstand seismic loading. Further, complicating the quantification of the Seismic Hazard for geoengineeringinduced events is that the full extent of the hazard is not fully known and varies with changes in geoengineering activities, locations, and technologies [2]. Thus, making induced seismic hazard maps and other measures is currently more subjective than quantitative. Furthermore, the Vulnerability is complicated by the age of the infrastructure, for example, dams, locks, levee, and so on. For example, the US Army Corps of Engineers oversees maintains or operates over 700 dams, 14,500 miles of levees, and 220 locks [23]. Most of these are aging facilities in need of constant repair and rehabilitation; eleven of these locks are in excess of 100 years old [23]. Such conditions lower the exceedance threshold within the Seismic Hazard and increase the fragility within the Vulnerability thereby, generating even greater Seismic Risk for small magnitude events, both on single-event and multiple event bases. Thus, a simplistic definitive statement of whether single or multiple small magnitudeinduced seismic events do or do not cause damage to critical infrastructure cannot be justified on the basis of comparative magnitudes between induced and tectonic events and warrants additional study, especially in respect to soil fatigue. However, recent observations and research suggest the likelihood that these geoengineering-induced events can and do cause detrimental degradation of the subsurface (damaging the overlying structure) is not insignificant.

\section{Conflicts of Interest}

The authors declare that they have no conflicts of interest.

\section{Acknowledgments}

The research was funded through the Assistant Secretary of the Army, Acquisition, Logistics and Technology (ASAALT) Military Engineering Direct Research program AT40 "Remote Assessment of Critical Infrastructure". Director, Geotechnical and Structures Laboratory, U.S. Army Engineer Research \& Development Center, granted permission to publish this research with unlimited distribution.

\section{References}

[1] O.-D. S. Taylor, A. P. Lester, and T. A. Lee, "Hazard and risk potential of unconventional hydrocarbon developmentinduced seismicity within the central United States," Natural Hazards Review, vol. 16, no. 4, p. 04015008, 2015.

[2] O.-D. S. Taylor, A. P. Lester, and T. A. Lee, Unconventional Hydrocarbon Development Hazards within the Central United States: Report 1: Overview and Potential Risk To Infrastructure, ERDC/GSL TR-15-26, U.S. Army Engineer Research and Development Center, Vicksburg, MS, USA, 2015.

[3] A. McGarr, "Maximum magnitude earthquakes induced by fluid injection," Journal of Geophysical Research: Solid Earth, vol. 119, no. 2, pp. 1008-1019, 2014.

[4] G. M. Atkinson, "Ground-motion prediction equation for smallto-moderate events at short hypocentral distances, with application to induced-seismicity hazards," Bulletin of the Seismological Society of America, vol. 105, no. 2A, pp. 981-992, 2015.

[5] W. L. Ellsworth, "Injection-induced earthquakes," Science, vol. 341, no. 6142, p. 1225942, 2013.

[6] T. R. Harper, "Effective stress history and the potential for seismicity associated with hydraulic fracturing of shale reservoirs," Journal of the Geological Society, vol. 171, no. 4, pp. 481-492, 2014.

[7] S. E. Hough, L. Seeber, and J. G. Armbruster, "Intraplate triggered earthquakes: observations and interpretations," Bulletin of the Seismological Society of America, vol. 93, no. 5, pp. 2212-2221, 2003.

[8] E. Brodsky and L. Lajoie, "Anthropogenic seismicity rates and operational parameters at the Salton Sea Geothermal Field," Science, vol. 341, no. 6145, pp. 543-546, 2013.

[9] H. Davis, KWCH12 News: Earthquakes Take Toll on Harper County Courthouse, June 2015, http://www.kwch.com/ news/local-news/earthquakes-take-toll-on-harper-countycourthouse/31183754.

[10] C. Frohlich, C. Hayward, B. Stump, and E. Potter, "The DallasFort Worth earthquake sequence: October 2008 through May 2009," Bulletin of the Seismological Society of America, vol. 101, no. 1, pp. 327-340, 2011.

[11] C. Frohlich, "Two-year survey comparing earthquake activity and injection-well locations in the Barnett Shale, Texas," Proceedings of the National Academy of Sciences: Earth, Planetary and Atmospheric Sciences, vol. 109, no. 35, pp. 13934-13938, 2012.

[12] C. Frohlich and M. Brunt, "Two-year survey of earthquakes and injection/production wells in the Eagle Ford Shale, Texas, prior to the Mw4.8 20 October 2011 earthquake," Earth and Planetary Science Letters, vol. 379, pp. 56-63, 2013.

[13] S. Horton, "Disposal of hydrofracking waste fluid by injection into subsurface aquifers triggers earthquake warm in Central 
Arkansas with potential for damaging earthquake," Seismological Research Letters, vol. 83, no. 2, pp. 250-260, 2012.

[14] W. Y. Kim, "Induced seismicity associated with fluid injection into a deep well in Youngstown, Ohio," Journal of Geophysical Research: Solid Earth, vol. 118, no. 7, pp. 3506-3518, 2013.

[15] C. D. Klose, "Human-riggered earthquakes and their impacts on human security, achieving environmental security: ecosystem services and human welfare," in NATO Science for Peace and Security Series-: Human and Societal Dynamics vol. 69, pp. 13-19, P. H. Liotta Ed., IOS Press, Amsterdam, Netherlands, 2010.

[16] L. Seeber, J. G. Armbruster, and W. Y. Kim, "A fluid-injectiontriggered earthquake sequence in Ashtabula, Ohio: implications for seismogenesis in stable continental regions," Bulletin of the Seismological Society of America, vol. 94, no. 1, pp. 76-87, 2004.

[17] J. H. Healy, W. W. Rubey, D. T. Griggs, and C. B. Raleigh, "The Denver earthquakes," Science, vol. 161, no. 3848, pp. 1301-1310, 1968.

[18] C. B. Raleigh, J. H. Healy, and J. D. Bredehoeft, “An experiment in earthquake control at Rangely, Colorado," Science, vol. 191, no. 4233, pp. 1230-1237, 1976.

[19] G. Atkinson, K. Assatourians, B. Cheadle, and W. Greig, "Ground motions for three recent earthquakes in Western Alberta and Northeastern British Columbia and their implications for induced-seismicity hazard in eastern regions," Seismological Research Letters, vol. 86, no. 3, pp. 1022-1031, 2015.

[20] G. Atkinson, H. Ghofrani, and K. Assatourians, "Impact of induced seismicity on the evaluation of seismic hazard: Some preliminary considerations," Seismological Research Letters, vol. 86, no. 3, pp. 1009-1021, 2015.

[21] Christian Science Monitor, Scientists: "Fracking" Should Be Part of Assessing Earthquake Hazards, October 2014, http://www. csmonitor.com/Environment/2014/0501/Scientists-Frackingshould-be-part-of-assessing-earthquake-hazards.

[22] J. K. Mitchell and R. A. Green, "Some induced seismicity considerations in geo-energy resource development," Geomechanics for Energy and the Environment, vol. 10, pp. 3-11, 2017.

[23] E. P. Chamberlayne, Risky Buisness: "Fracking" and U.S. Army Infrastructure, Civilian Research Project, Army War College Fellow, United States Army War College, Carlisle, PA, USA, 2015.

[24] R. R. Burchett, K. V. Luza, O. J. Van Eck, and F. W. Wilson, Seismicity and Tectonic Relationships of the Nemaha Uplift and Midcontinent Geophysical Anomaly (Final Project Summary). Vol. 4, Special Publication 85-2, Oklahoma Geological Survey, Norman, OK, USA, 1985.

[25] K. M. Keranen, H. M. Savage, G. A. Abers, and E. S. Cochran, "Potentially induced earthquakes in Oklahoma, USA: links between wastewater injection and the $2011 \mathrm{Mw} 5.7$ earthquake sequence," Geology, vol. 41, no. 6, pp. 699-702, 2013.

[26] K. M. Keranen, M. Weingarten, G. Abers, B. Bekins, and S. Ge, "Sharp increase in central Oklahoma seismicity since 2008 induced by massive wastewater injection," Science, vol. 345 , no. 6195 , pp. 448-451, 2014.

[27] B. Oskin, Fracking-Linked Earthquakes May Strike Far From Wells, Live Science, May 2014, http://www.livescience.com/ 45322-fracking-wastewater-farther-earthquakes.html.

[28] C. Ramsay, 4.3 Magnitude Earthquake Hits Near Rocky Mountain House, Global News, August 2014, http://globalnews. $\mathrm{ca} /$ news/1501147/earthquake-hits-northeast-of-rocky-mountainhouse-power-outages-reported/.

[29] C. Frolich, W. Ellsworth, W. Brown et al., "The 17 May 2012 M 4.8 earthquake near Timpson, East Texas: an event possibly triggered by fluid injection," Journal of Geophysical Research: Solid Earth, vol. 119, no. 1, pp. 581-593, 2014.
[30] J. Malewitz, After Surprise Quakes, North Texans Speak of Impact, The Texas Tribune, Austin, TX, USA, June 2014, http:// www.texastribune.org/2014/01/03/texans-seek-answers-drillingslink-earthquakes/.

[31] USGS-U.S. Geologic Survey, Cherokee Oklahoma Earthquake Did You Feel It Archive Page, U.S. Geological Survey, Reston, VA, USA, June 2015, http://earthquake.usgs.gov/earthquakes/ dyfi/events/us/c000tmeb/us/index.html.

[32] Associated Press, Quake Slightly Damages Alfalfa County Courthouse, Muskogee Phoenix, June 2015, http://www. muskogeephoenix.com/news/oklahoma_news/quake-slightlydamages-alfalfa-county-courthouse/article_e199f496-adc411e4-884a-978d3fa3aa8a.html.

[33] D. Lefler, The Wichita Eagle 2014: Kansans Clean up after Magnitude-4.8 Earthquake Shakes Wichita, Southern Part of State, November 2014, http://www.kansas.com/news/local/ article3847222.html.

[34] A. Bickel, Age, Quakes Escalate Damage at Harper Co. Courthouse at More Than \$1.1M, Kansas Agland, June 2015, http://www.kansasagland.com/news/stateagnews/age-quakesescalate-damage-at-harper-co-courthouse-at-more/article_ 7d0f1168-4832-56a5-8236-2fe1f538590a.html.

[35] USGS-U.S. Geologic Survey, Kansas 4.9 Earthquake, U.S. Geological Survey, Reston, VA, USA, June 2015, http://earthquake. usgs.gov/earthquakes/eventpage/usc000swru\#general_summary.

[36] J. Mack, Michigan Earthquake Causes Minor Building Damage Near Galesburg Epicenter, Mlive, June 2015, http://www. mlive.com/news/kalamazoo/index.ssf/2015/05/michigan_ earthquake_causes_min.html.

[37] USGS-U.S. Geologic Survey, M4.2-8 km S of Galesburg, U.S. Geological Survey, Lansing, MI, USA, June 2015, http:// earthquake.usgs.gov/earthquakes/eventpage/us20002avh\#scientific_ summary.

[38] M. C. L. Quinn and O.-D. S. Taylor, "Hazard topography: visual approach for identifying critical failure combinations for infrastructure," Natural Hazards Review, vol. 15, no. 4, p. 04014012, 2014.

[39] O.-D. S. Taylor, "Use of an energy-based liquefaction approach to predict deformation in silts due to pile driving," $\mathrm{Ph} . \mathrm{D}$. dissertation, University of Rhode Island, Kingston, RI, USA, 2011.

[40] J. J. Bommer, B. Dost, B. Edwards et al., "Developing an application-specific ground-motion model for induced seismicity," Bulletin of the Seismological Society of America, vol. 106, no. 1, pp. 158-173, 2016.

[41] D. E. Hudson, Reading and Interpreting Strong Motion Accelerograms, Earthquake Engineering Research Institute, Berkeley, CA, USA, 1979.

[42] M. F. Riemer, W. B. Gookin, J. D. Bray, and I. Arango, Effects of Loading Frequency and Control on the Liquefaction Behavior of Clean Sands, Geotechnical Engineering Rep. UCB/ GT/94-07, University of California, Berkeley, CA, USA, 1994.

[43] R. Green and G. Terri, "Number of equivalent cycles concept for liquefaction evaluations-revisited," Journal Geotechnical and Geoenviromental Engineering, vol. 131, no. 4, pp. 477-488, 2005.

[44] H. B. Seed and I. M. Idriss, "Simplified procedure for evaluating soil liquefaction potential," Journal of the Soil Mechanics and Foundations Division, vol. 97, no. SM9, pp. 1249-1273, 1971.

[45] H. B. Seed, I. M. Idriss, F. Makdisi, and N. Banerjee, Representation of Irregular Stress Time Histories by Equivalent Uniform Stress Series in Liquefaction Analysis, Tech. Rep. EERC 75-29, Earthquake Engineering Research Center, College of Engineering, University of California, Berkeley, CA, USA, 1975.

[46] Z. Wang, "Seismic hazard assessment: issues and alternatives," Pure and Applied Geophysics, vol. 168, no. 1-2, pp. 11-25, 2010. 


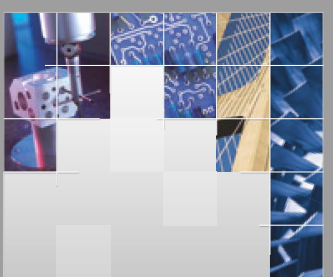

\section{Enfincering}
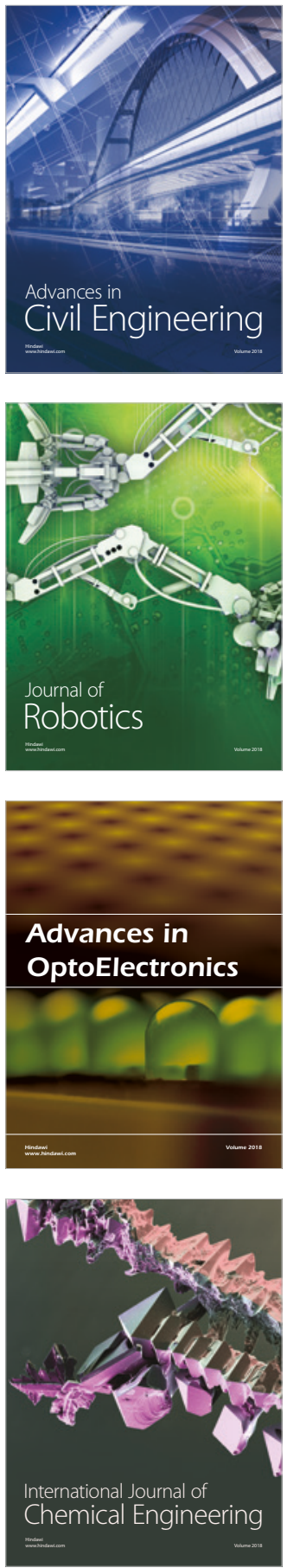

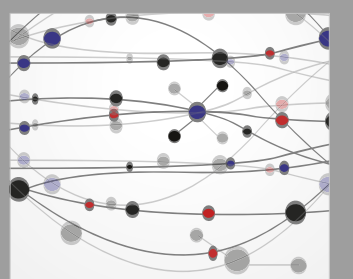

\section{Rotating \\ Machinery}

The Scientific World Journal

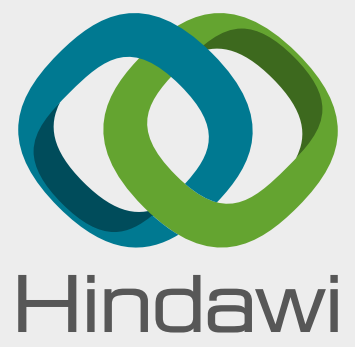

Submit your manuscripts at

www.hindawi.com
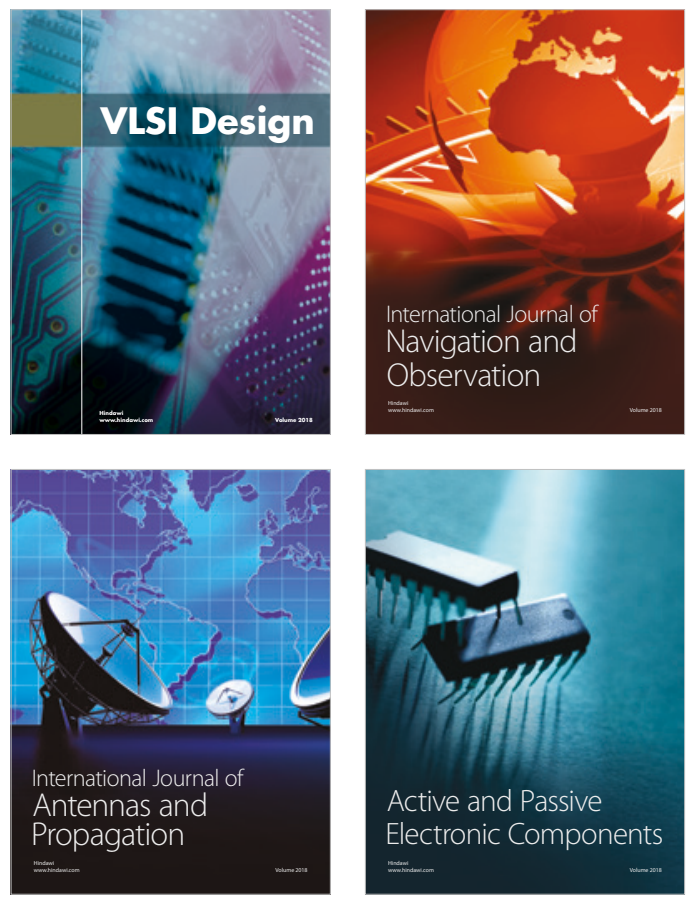
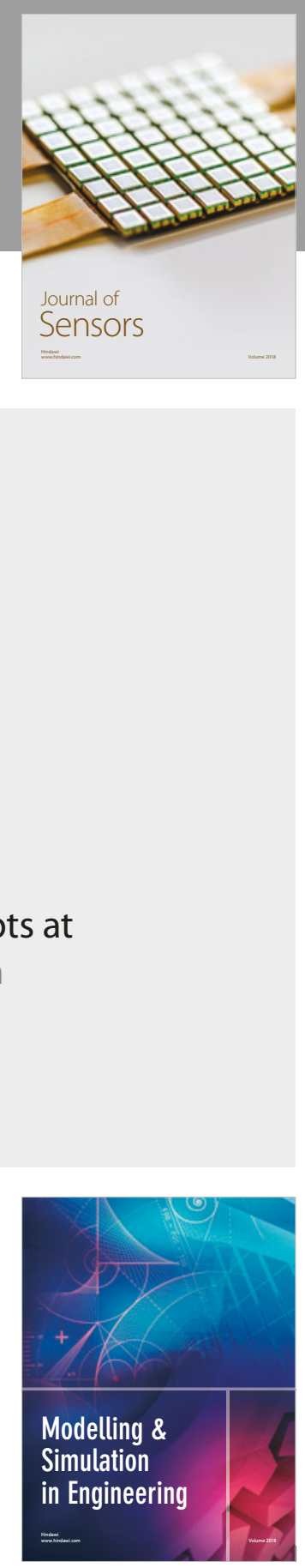

\section{Advances \\ Multimedia}
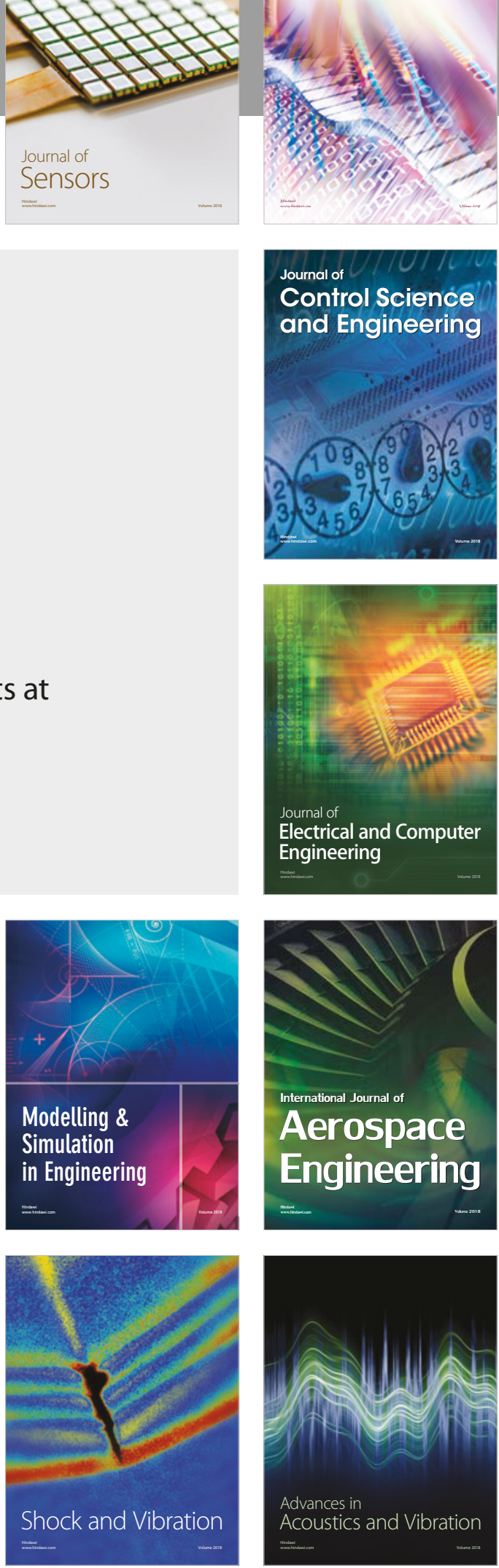